\title{
Trajectories of Home Nursing Use for Older Women in Melbourne,
}

\section{Australia: 2006-2015}

\author{
(1) \\ Marissa Dickins ${ }^{\mathrm{a}, \mathrm{b}}$, Angela Joe ${ }^{\mathrm{a}}$, Joanne Enticott ${ }^{\mathrm{b}, \mathrm{c}, \mathrm{d}}$, Rajna Ogrin $^{\mathrm{a}, \mathrm{e}, \mathrm{f}, \mathrm{g}, \mathrm{J}}$ Judy Lowthian ${ }^{\mathrm{a}, \mathrm{h}, \mathrm{i}, \mathrm{j}}$ \\ a Bolton Clarke Research Institute; 973 Nepean Highway, Bentleigh, VIC 3204, Australia
}

b Southern Synergy, Department of Psychiatry at Monash Health, Southern Clinical School, Monash University; 126-128 Cleeland St, Dandenong VIC 3175, Victoria, Australia

c Department of General Practice, School of Primary and Allied Health Care, Monash University, Australia

d Monash Partners Advanced Health Research and Translation Centre, Melbourne, Australia

e Department of International Business and Asian Studies, Griffith University, Brisbane, Australia

f Biosignals for Affordable Healthcare, Royal Melbourne Institute of Technology University, Melbourne, Australia

g Austin Health Department of Medicine, University of Melbourne, Melbourne, Australia

h School of Public Health and Preventive Medicine, Monash University, Melbourne, Australia

i Faculty of Health and Behavioural Sciences, University of Queensland, Brisbane, Australia

j Institute of Future Environments, Queensland University of Technology, Brisbane, Queensland

Corresponding Author: Dr Marissa Dickins, Bolton Clarke Research Institute, Suite 1.01, 973 Nepean

Highway, Bentleigh, VIC 3204, Victoria, Australia. Email: mdickins@boltonclarke.com.au , phone: $+61385312563$

Word Count: 2,896 words

Acknowledgements

This research was supported by the Lord Mayor's Charitable Foundation - Eldon \& Anne Foote Trust. The authors declare no conflicts of interest.

This is the author manuscript accepted for publication and has undergone full peer review but has not been through the copyediting, typesetting, pagination and proofreading process, which may lead to differences between this version and the Version of Record. Please cite this article as doi: 10.1111/AJAG.12735

This article is protected by copyright. All rights reserved 


\section{Policy Impact Statement}

This paper highlights the increasing complexity of older women accessing home nursing services in Australia. This also increases the complexity of care that is required in the community. The information provided within this paper has the potential to inform planning and policy change to ensure adequate resources are available into the future.

-

\section{Practice Impact Statement}

This paper highlights the increasing complexity of older women accessing home nursing services in Australia. This also increases the complexity of care that is required in the community. The information provided within this paper has the potential to inform planning for service providers into the future, and to assist providers in understanding their changing customers.

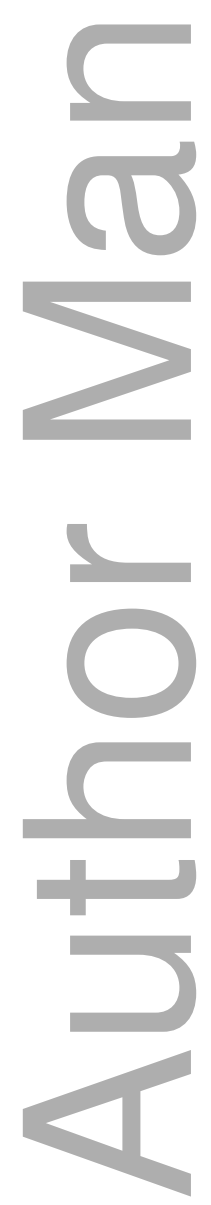


DR. MARISSA DICKINS (Orcid ID : 0000-0001-8049-2540)

DR. JUDY LOWTHIAN (Orcid ID : 0000-0002-9780-5256)

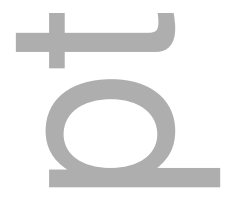

Article type : Research Article

Trajectories of Home Nursing Use for Older Women in Melbourne, Australia: 2006-2015

\section{Abstract}

\section{Objective}

To profile changes in older women accessing home nursing between 2006 and 2015, focussing on living circumstances.

\section{Methods}

Data pertaining to Australian women aged 55+ who accessed a home nursing service between 20062015 were analysed, stratified by living status. Comparisons were made between the years 2006 and 2015; rates and relative rates of use per 1,000 clients calculated.

Results

Fewer women lived alone in 2015 compared with 2006. Women were older, less likely to be born in Australia, speak English at home, had more diagnoses and higher average Charlson Comorbidity Index scores in 2015. Relative rates of service use for older women living with others increased slightly over the 10 -years, while decreasing by $13 \%$ for those living alone.

\section{Conclusion}

Women using home nursing services are older than previously, more medically complex, more likely to be born from countries other than Australia and speak a preferred language other than English. 
Key words

Home nursing, district nursing, women, older, living alone

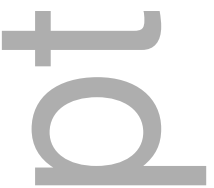

\section{Introduction}

We are an ageing population. Due to declining death rates and improved healthcare standards, individuals are ageing beyond previous thresholds. $[1,2]$ This is particularly true in Australia and many other high income countries, as the 'baby boomer' generation (those born between 1946 and 1966) move into retirement age. Improved life expectancy does not mean, however, that individuals are living without disease or disability; almost a third of individuals over the age of 85 experience two or more health conditions.[3] The most common conditions for individuals aged 65 and older include cardiovascular disease, cancer and neurological conditions.[4]

Financial decline, multiple comorbidities, and reduced social engagement due to living alone, may all contribute negatively on the health and wellbeing of older people as they age. $[5,6]$ However, women and men experience ageing differently.[7] Women live longer than men, and are more likely to spend their final years without their partner. $[1,8,9]$ Increases in the number of women who have never married or had children are the result of a complex web of choice (to not marry or remain childless), circumstances (infertility, not meeting an appropriate partner, identifying as being attracted to persons of the same sex) and changing social norms (such as the introduction and acceptance of divorce and same-sex marriage). These factors also add to the likelihood that women will live alone in their older years compared with men. Furthermore, women are at significant financial disadvantage due to caring responsibilities, lower pay and reduced work hours, which translates into economic insecurity in older age.[5]

Most individuals wish to age-in-place, that is, they aim to remain in their own home as long as possible as they age.[10,11] However, older individuals may develop any number of cognitive, psychological, social or physical issues that may impede their ability to do so. $[5,10,12]$ This is particularly true for older women living alone, who are less likely to age-in-place and access preventive care than those living with a spouse.[10] Despite this, previous research has shown that demand for aged care services increases with age, [13] where usage reaches approximately $50 \%$ of Australians over the age of 65.[14] Further, older women living alone are more likely than their 
counterparts living with others to use aged care services within the community.[15] There has been little research, however, to examine the trends of community services such as home nursing care usage for women over time.[5] This is due to many factors, including under-representation in research - particularly those who are ill or frail.[3] This study aims to address this gap by utilising routinely collected administrative data to understand how older women's use of home nursing has changed over a 10-year period, with a focus on living circumstances.

\section{Methods}

This study is reported in accordance with the REporting of studies Conducted using Observational Routinely-collected health Data (RECORD) Statement.[16]

This analysis reports on a sub-study of an overarching project entitled Older Women Living Alone. This two-year project aimed to optimise the health and wellbeing of older women through the codesign of services with older women based on evidence. There is a paucity of research in this area, and as such the research team triangulated data from a systematic review, interviews with older women, and analysis of routine administrative data to inform the codesign process.[17]

\section{Study design and setting}

We conducted a retrospective analysis of routine administrative data collected by a not-for-profit organisation delivering home nursing care services in Victoria, Australia. The organisation primarily provides services to metropolitan Melbourne, Australia, with limited services provided to rural localities within Victoria. Access to these services was through programs subsidized by State or Federal government funding or through private arrangement.[18]

\section{Participants and data source}

A comprehensive, de-identified data set describing clients and their service use was provided to researchers for each of the ten years between 2006 and 2015. The study sample consisted of women aged 55 years or older. Analyses were limited to the first admission for each year. Minimal data cleaning was required, primarily consisting of collapsing variables into meaningful groups (e.g. language, country of birth).

\section{Socioeconomic data}

Sociodemographic data comprised: age, country of birth, preferred language, living situation and whether the client had a carer. Status relating to 'living alone' was derived for each calendar year, with a status of 'living alone' allocated to a woman if she was recorded as living alone at any point within that year. The Index of Relative Socio-Economic Disadvantage (IRSD) deciles for Victoria 
provided by the Australian Bureau of Statistics (ABS) were used as a proxy for the client's socioeconomic status, through linkage with the client's residential postcode.[19] A high decile indicates an area of low disadvantage, while a low decile indicates an area of high disadvantage.

\section{Service data}

Service data included referral source, discharge location, and goal of care. As part of service provision, staff work with clients to outline a goal for their care. This is then noted as 'Achieved' or 'Not Achieved' at discharge.

\section{Diagnoses data}

The International Classification of Disease (ICD) was used to document diagnoses in the client records. Both ICD-9[20] and ICD-10[21] codes were present in the data due to the time frame of the study. Where ICD-9 codes were present they were incorporated under the ICD-10 code structure. In addition, the Charlson Comorbidity Index (CCI)[22] was calculated for each individual as a proxy for the client's overall burden of disease.[23] The CCI predicts the risk of mortality for an individual at 12 months, based on their diagnoses.

\section{Statistical analyses}

To examine the changing sociodemographic, service, and diagnostic profiles over time for women aged 55 years and over, the years 2006 and 2015 were compared using descriptive statistics. Chi square tests for independent samples were used to analyse categorical data. Continuous data were analysed using t-tests for independent samples. Comparisons of living alone status across years were conducted with chi square goodness-of-fit tests. Given the large size of the data set, a more conservative $p$ value of 0.001 was used for analyses,[24] and chi square was run for smaller groups (e.g. older women living alone in 2006 compared with older women living alone in 2015). Rates and relative rates per 1,000 clients (all client ages and sexes) in each of the 10 years were calculated by living alone status; relative rates were calculated by age group.

\section{Ethical approval}

This study was approved by the Bolton Clarke Human Research Ethics Committee, Approval Number 170003. When a client is admitted to the nursing service, consent is sought to use their data for research in an opt-out basis; individuals who did not provide consent were removed from the database before data were provided to the research team. Less than one percent of individuals who received services did not provide consent for research. 


\section{Results}

\section{Study cohort characteristics}

Between 2006 and 2015, 72,993 women aged 55 or over accessed the home nursing service. In 2006 there were 10,030 women admitted to the service, and in 2015 there were 10,274. The findings from the sociodemographic, service and diagnosis profiles are summarized below in Figure 1.

Sociodemographic profile

Approximately two-fifths of women lived alone in both 2006 (42.5\%) and 2015 (39.3\%), with this difference being statistically significant $(\chi 2(1, n=10,274)=43.24, p<0.001 ;$ Table 1$)$. In comparing 2006 with 2015, both older women living alone and older women living with others in 2015 were older (alone $t(8,304)=-4.83, p<0.001$; others $t(11,996)=-4.10, p<0.001)$. In addition, the proportion of individuals receiving home nursing care who were born in Australia (alone x2 (2, $n=8,306)=223.91, p<0.001$; others $\chi 2(2, n=11,998)=388.74, p<0.001)$, or spoke English as their preferred language (alone $\chi 2(1, n=8,306)=14.33, p<0.001$; others $\chi 2(1, n=11,998)=5.42, p=$ $0.020)$ decreased over time. Over the ten-year period women living alone were gradually less likely to live in areas of least socioeconomic disadvantage (alone $\chi 2(5, n=8,306)=28.08, p<0.001$; others $\chi 2(5, n=11,998)=2.92, p=0.713)$. Older women living alone were less likely to have a carer ( $\chi 2(9$, $n=8,306)=40.97, p<0.001$ ), while no significant changes in carer status were observed for those living with others $(x 2(9, n=11,998)=16.12, p=0.064)$.

\section{INSERT Table 1 ABOUT HERE}

\section{Service use profile}

In 2015 , both women living alone and those living with others were less likely to achieve their care goal when compared to 2006 (alone $\chi 2(1, n=8,306)=201.76, p<0.001$; others $\chi 2(1, n=11,998)=$ 28.16, $p<0.001$; Table 2). Women living alone were more likely to be referred to the home care service by a hospital or palliative care, but less likely to be referred by a doctor or subacute care in 2015 than in $2006(x 2(7, n=8,306)=275.70, p<0.001)$. Conversely, women living with others were less likely to be referred to the home care service by a hospital, doctor or subacute care, but more likely to be referred by palliative care in 2015 compared with $2006(\chi 2(7, n=11,998)=283.18, p<$ 0.001). Women living alone were less likely to be discharged to home and more likely to be discharged to hospital in 2015 compared with 2006, while the opposite was true for those living with others (alone $\chi 2(6, n=8,306)=271.99, p<0.001$; others $\chi 2(6, n=11,998)=237.44, p<0.001)$

\section{INSERT Figure 1 ABOUT HERE}




\section{Diagnosis profile}

Women living alone and women living with others had significantly more diagnoses in 2015 compared with 2006 (alone, $t(8,289)=-17.89, \mathrm{p}<0.001$; others $t(11,853)=-15.19, \mathrm{p}<0.001 ;$ Table 3). In addition, there was a significant increase in CCl scores between 2006 and 2015 for both those living alone $(t(8,289)=-6.91, p<0.001)$ and those living with others $(t(11,853)=-5.80, p<0.001)$.

\section{INSERT Table 3 ABOUT HERE}

\section{Rates of service use}

Rates and relative rates per 1,000 service users (of all ages and sexes) across the 10-year period are presented in Figure 2. Rates of service use by women living alone decreased from 193 to 168 per 1000 home nursing clients from 2006 to 2015; for women living with others over this period, service use ranged from 261 to 259 per 1000 service users (Figure 2a). The trend across the 10 years, as shown by relative rates, revealed that while women living with others slightly increased their use of the home nursing service, women living alone showed progressive decline in accessing services with approximately 13\% less service utilization in 2015 compared with 2006 (Figure 2b).

\section{INSERT Figure 2 ABOUT HERE}

Relative rates of service use, when categorized into 10-year age groups, showed a clear delineation between those under and over the age of 85 . For those living with others (Figure $2 \mathrm{~d}$ ), service use increased by $20-25 \%$ in those aged over 85 between 2006 and 2015, while those aged 65-74 indicated relatively stable rates over the 10 years. Service use decreased in the 55-64 and 75-84 age groups by approximately 11-13\% over the study period. For those living alone (Figure $2 \mathrm{c}$ ), the oldest age group (aged 95+) saw the largest increase; with a 33\% rise in service use between 2006 and 2015. This was followed by those aged $85-94$ whose use increased $9 \%$ over 10 -years. In the youngest age groups, relative rates dropped by approximately $12 \%$; while those aged $75-84$ saw the largest drop; 33\% between 2006 and 2015.

\section{Discussion}

Rates of older women living alone accessing a large Melbourne-based home nursing service decreased over a ten-year period (from 194 per 1000 in 2006 to 168 per 1000 in 2015), while the rate of service usage by older women who lived with others was essentially unchanged (i.e. 260 per 1000 in 2006 and 2015). Overall, in older women clients, there was a decrease in nursing service utilisation by those who lived alone from $42.5 \%$ in 2006 to $39.3 \%$ in 2015 . While this finding represents a statistically significant reduction, this may be due to the large size of the data set. This 
is particularly salient when compared with population trends, which suggest that older women living alone has remained relatively stable in the general Australian population.[25] Older women in 2015 had a higher average age compared to 2006 , and while women living alone were less likely to live in areas of least socioeconomic disadvantage, there was no change over time for women living with others. Furthermore, the proportion of older women born in Australia decreased over time, as did their likelihood of speaking English as their preferred language - regardless of living status. This is consistent with current trends in the Australian population over recent years as baby boomers and post-war migrants move into retirement age.[1, 4, 25]

The complexity of health issues of all women accessing the home nursing service increased over the ten-year period. Women living alone were less likely to be discharged from the home nursing service to home, and more likely to be discharged from home nursing care to hospital in 2015 , while the opposite was true for women living with others. This was reinforced by an overall decline in rates of service use for women living alone over the ten-year period, and a reduction in the proportion who achieved their care goal. Furthermore, all women receiving home nursing care had more diagnoses on average, and their $\mathrm{CCl}$ score increased over time. These findings are supported by previous research indicating that as our medical knowledge grows and care improves, individuals will live longer with multiple comorbidities, leading to greater complexity and need for supports.[3, 26, 27] Our study indicates that once older women living alone engage with home nursing services they are likely to decline rather than maintain health, unlike older women living with others. These findings may be due to many factors but reflect knowledge that the diminished support that often occurs for those living alone results in unexpected deterioration and increased likelihood of hospitalization and/or requirement for residential aged care for older individuals.[28, 29]

There appeared to be an overall decline of $13 \%$ in service use by older women living alone between 2006 and 2015, while use of the home nursing service by older women living with others appeared relatively steady across this period. Interestingly, when utilization data was stratified by age, it became very apparent that use of the service was age-dependent. The decrease in service utilization for those living alone was driven by those under the age of 85 , with a particularly large decline for women aged 65-74 years. In contrast to the overall trend of declining service usage by women living alone, those women living alone who were aged 85 and over showed increased utilization of home nursing care over the 10-year period. Similarly, for older women living with others, those women aged under 85 exhibited decreased or steady use of the nursing service, while those living with others aged 85 or over markedly increased their use of the service from 2006 to 2015. In the context of the findings related to service and diagnoses trajectories outlined above, these results are concerning. This is particularly true considering the purpose of community-based services - to 
maintain independence and optimize wellbeing while allowing individuals to age-in-place. The reasons for the reduction in service usage by women younger than 85 requires further investigation, as does the ramifications of this on the health of these women, their loved ones, and the health system overall.

The substantial increases (10\%-33\%) in service use for women over the age of 85 , regardless of living status, is consistent with previous research that revealed the demand for aged care services such as home nursing increases with age.[13] This may be due to many factors, some of which were identified in our study, such as increasing medical complexity, and increased proportion of individuals speaking languages other than English. Other factors may also play a part in these changes in service use, such as changes to government funding for home nursing and other health services over time.

This is the first paper to examine the use of home nursing services over time for women, and to analyse underlying factors by living situation. An additional strength is that the data set was comprehensive, with minimal data cleaning required. This reflects the primary purpose of the data set, which was to inform the delivery of nursing services within the community. There are some limitations that need to be considered alongside the findings. This analysis is of secondary data that was collected for purposes other than for research, meaning that incomplete information may not have been included in the analysis and misreported information included. Furthermore, the large size of the data set may have resulted in findings that are statistically significant, but not meaningful when taken in context.

\section{Conclusion}

As the older cohort of individuals increases, understanding their changing needs is imperative to help service providers plan how best to support older individuals. Women using home nursing services are older than a decade ago, and are also more medically complex, more likely to originate from countries other than Australia and speak languages other than English. This all adds to the complexity and support required to care for these individuals in their own homes. Further research is required to understand the underlying mechanisms that drive this complexity and associated service use, and their impact on older women's ability to age-in-place over time.

\section{References}

1. Australian Bureau of Statistics. Ageing Population, 2016. Canberra; 2017. 
2. World Health Organisation. Life expectancy Geneva: World Health Organisation; n.d. [Available

from:

https://www.who.int/gho/mortality burden disease/life tables/situation trends text/en/].

3. Australian Institute of Health and Welfare. Australia's Health 2016. Canberra: Australian Institute of Health and Welfare; 2016.

4. Australian Institute of Health and Welfare. Older Australia at a glance. Canberra: Australian Institute of Health and Welfare; 2018.

5. Feldman S, Radermacher H. Time of our lives? Building opportunity and capacity for the economic and social participation of older Australian women. Lord Mayor's Charitable Foundation; 2016.

6. Kharicha K, Iliffe S, Harari D, Swift C, Gillmann G, Stuck AE. Health risk appraisal in older people 1: are older people living alone an 'at-risk' group? British Journal of General Practice. 2007;57(537):271.

7. Browning CJ, Enticott JC, Thomas SA, Kendig HAL. Trajectories of ageing well among older Australians: a 16-year longitudinal study. Ageing and Society. 2017;38(8):1581-602. $10.1017 / \mathrm{S} 0144686 \times 17000162$.

8. Australian Bureau of Statistics. TableBuilder Canberra: Australian Bureau of Statistics; 2018 [Available from: http://www.abs.gov.au/websitedbs/censushome.nsf/home/tablebuilder].

9. Australian Bureau of Statistics. Australian Historical Population Statistics, 2014 Canberra: Australian Bureau of Statistics; 2014 [September 18]. Available from: http://www.abs.gov.au/AUSSTATS/abs@.nsf/Lookup/3105.0.65.001Main+Features12014?OpenDoc ument].

10. Kendig H, Gong CH, Cannon L, Browning C. Preferences and Predictors of Aging in Place: Longitudinal Evidence from Melbourne, Australia. Journal of Housing For the Elderly. 2017:1-13. 10.1080/02763893.2017.1280582.

11. Olsberg D, Winters M. Ageing in place: intergenerational and intrafamilial housing transfers and shifts in later life. Melbourne; 2005.

12. Cohen-Mansfield J, Perach R. Interventions for alleviating loneliness among older persons: a critical review. American journal of health promotion : AJHP. 2015;29(3):e109-25. 10.4278/ajhp.130418-LIT-182.

13. Rahman M, Efird JT, Byles JE. Patterns of aged care use among older Australian women: A prospective cohort study using linked data. Archives of gerontology and geriatrics. 2019;81:39-47. 10.1016/j.archger.2018.11.010.

This article is protected by copyright. All rights reserved 
14. Australian Government Department of Social Services. Home and Community Care Program Minimum Data Set 2013-14 Annual Bulletin. Canberra: Australian Government Department of Social Services; 2014.

15. Jorm LR, Walter SR, Lujic S, Byles JE, Kendig HL. Home and community care services: a major opportunity for preventive health care. BMC Geriatrics. 2010;10(1):26. 10.1186/1471-2318-10-26.

16. Benchimol El, Smeeth L, Guttmann A, et al. The REporting of studies Conducted using Observational Routinely-collected health Data (RECORD) Statement. PLOS Medicine. 2015;12(10):e1001885. 10.1371/journal.pmed.1001885.

17. Ogrin R, Lowthian JA, Johnstone $\mathrm{G}$, et al. Older Women Living Alone: co-creating health and social care services. 51st Australian Association of Gerontology Conference; 21-23 November; Melbourne, Australia: 2018.

18. Australian Government. Home Care Packages 2016 [October 14]. Available from: http://www.myagedcare.gov.au/aged-care-services/home-care-packages].

19. Pink B. Technical paper Socio-Economic Indexes for Areas (SEIFA) 2011. Canberra: Australian Bureau of Statistics; 2013.

20. National Center for Health Statistics, Centers for Medicare \& Medicaid Services. The International Classification of Diseases, 9th Revision, Clinical Modification 2008 [6th:[Available from: http://icd9.chrisendres.com/index.php].

21. World Health Organisation. ICD-10 Version: 2010 Geneva: World Health Organisation; 2010 [Available from: http://apps.who.int/classifications/icd10/browse/2010/en].

22. Sundararajan V, Henderson T, Perry C, Muggivan A, Quan H, Ghali WA. New ICD-10 version of the Charlson comorbidity index predicted in-hospital mortality. Journal of Clinical Epidemiology. 2004;57(12):1288-94. 10.1016/j.jclinepi.2004.03.012.

23. Huntley AL, Johnson R, Purdy S, Valderas JM, Salisbury C. Measures of Multimorbidity and Morbidity Burden for Use in Primary Care and Community Settings: A Systematic Review and Guide. Annals of Family Medicine. 2012;10:134-41. 10.1370/afm.1363.

24. Palesch YY. Some common misperceptions about p-values. Stroke. 2014;45(12):e244-e6. 10.1161/STROKEAHA.114.006138.

25. de Vaus D, Qu L. Demographics of living alone. Melbourne: Australian Institute of Family Studies; 2015. Contract No.: 6.

26. Australian Institute of Health and Welfare. Australia's Health 2018. Canberra: Australian Institute of Health and Welfare; 2018.

This article is protected by copyright. All rights reserved 
27. World Health Organisation. Ageing and health Geneva: World Health Organisation; 2018 [February 5]. Available from: http://www.who.int/news-room/fact-sheets/detail/ageing-andhealth].

28. Mahoney JE, Eisner J, Havighurst T, Gray S, Palta M. Problems of older adults living alone after hospitalization. Journal of general internal medicine. 2000;15(9):611-9. 10.1046/j.15251497.2000.06139.x.

29. Mu C, Kecmanovic M, Hall J. Does Living Alone Confer a Higher Risk of Hospitalisation? Economic Record. 2015;91(S1):124-38. 10.1111/1475-4932.12184.

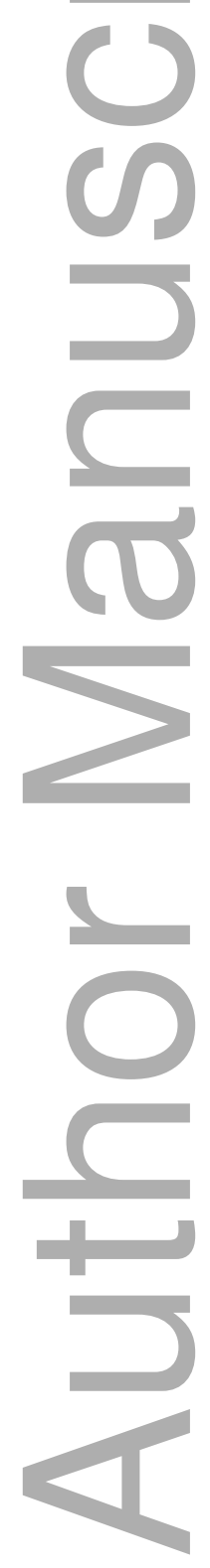

This article is protected by copyright. All rights reserved 


\section{Tables}

Table 1. Sociodemographic profile of women aged 55 years and older by living alone status in 2006 and 2015

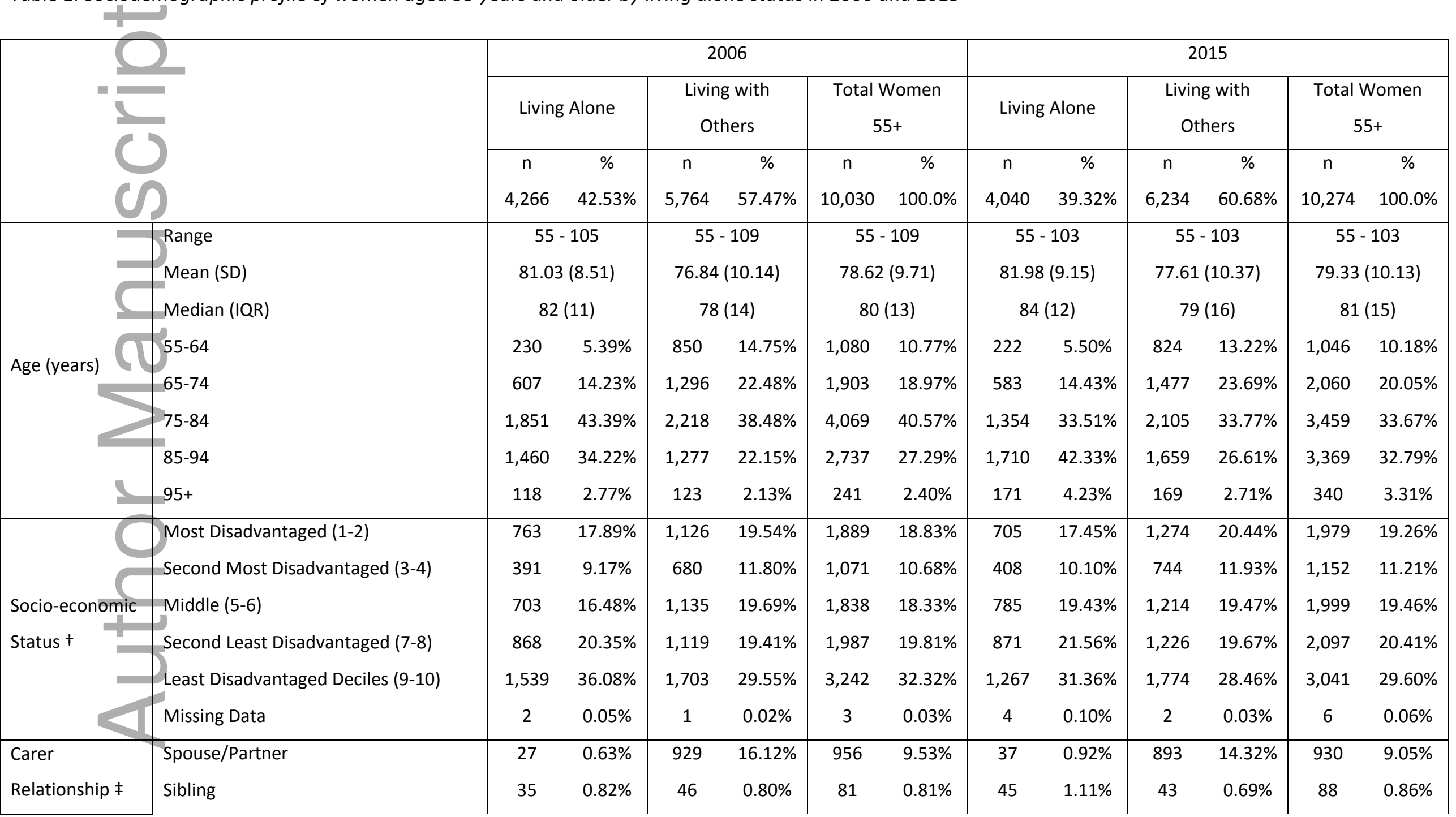

This article is protected by copyright. All rights reserved 


\begin{tabular}{|c|c|c|c|c|c|c|c|c|c|c|c|c|c|}
\hline & Offspring & 902 & $21.14 \%$ & 1,242 & $21.55 \%$ & 2144 & $21.38 \%$ & 1,046 & $25.89 \%$ & 1,395 & $22.38 \%$ & 2441 & $23.76 \%$ \\
\hline & Grandchild & 36 & $0.84 \%$ & 35 & $0.61 \%$ & 71 & $0.71 \%$ & 33 & $0.82 \%$ & 40 & $0.64 \%$ & 73 & $0.71 \%$ \\
\hline & Parent & 3 & $0.07 \%$ & 5 & $0.09 \%$ & 8 & $0.08 \%$ & 3 & $0.07 \%$ & 12 & $0.19 \%$ & 15 & $0.15 \%$ \\
\hline & n-Laws & 54 & $1.27 \%$ & 86 & $1.49 \%$ & 140 & $1.40 \%$ & 68 & $1.68 \%$ & 88 & $1.41 \%$ & 156 & $1.52 \%$ \\
\hline & Other Family & 70 & $1.64 \%$ & 78 & $1.35 \%$ & 148 & $1.48 \%$ & 67 & $1.66 \%$ & 103 & $1.65 \%$ & 170 & $1.65 \%$ \\
\hline & Friends & 76 & $1.78 \%$ & 47 & $0.82 \%$ & 123 & $1.23 \%$ & 51 & $1.26 \%$ & 43 & $0.69 \%$ & 94 & $0.91 \%$ \\
\hline & Professional Carers & 62 & $1.45 \%$ & 61 & $1.06 \%$ & 123 & $1.23 \%$ & 39 & $0.97 \%$ & 48 & $0.77 \%$ & 87 & $0.85 \%$ \\
\hline & No Carer Required & 3,001 & $70.35 \%$ & 3,235 & $56.12 \%$ & 6236 & $62.17 \%$ & 2,651 & $65.62 \%$ & 3,569 & $57.25 \%$ & 6220 & $60.54 \%$ \\
\hline & English & 3,759 & $88.12 \%$ & 4,468 & $77.52 \%$ & 8,227 & $82.02 \%$ & 3,446 & $85.30 \%$ & 4,720 & $75.71 \%$ & 8,166 & $79.48 \%$ \\
\hline & Eastern Asian Languages & 12 & $0.28 \%$ & 53 & $0.92 \%$ & 65 & $0.65 \%$ & 17 & $0.42 \%$ & 104 & $1.67 \%$ & 121 & $1.18 \%$ \\
\hline & Eastern European Languages & 142 & $3.33 \%$ & 236 & $4.09 \%$ & 378 & $3.77 \%$ & 133 & $3.29 \%$ & 212 & $3.40 \%$ & 345 & $3.36 \%$ \\
\hline & Northern European Languages (Excl. & 27 & $0.63 \%$ & 38 & $0.66 \%$ & 65 & $0.65 \%$ & 16 & $0.40 \%$ & 16 & $0.26 \%$ & 32 & $0.31 \%$ \\
\hline & Southeast Asian Languages & 5 & $0.12 \%$ & 59 & $1.02 \%$ & 64 & $0.64 \%$ & 9 & $0.22 \%$ & 100 & $1.60 \%$ & 109 & $1.06 \%$ \\
\hline Preferred & Southern Asian Languages & 2 & $0.05 \%$ & 22 & $0.38 \%$ & 24 & $0.24 \%$ & 3 & $0.07 \%$ & 41 & $0.66 \%$ & 44 & $0.43 \%$ \\
\hline Language*§ & Southern European Languages & 257 & $6.02 \%$ & 597 & $10.36 \%$ & 854 & $8.51 \%$ & 314 & $7.77 \%$ & 664 & $10.65 \%$ & 978 & $9.52 \%$ \\
\hline & Central Asian & 13 & $0.30 \%$ & 62 & $1.08 \%$ & 75 & $0.75 \%$ & 34 & $0.84 \%$ & 108 & $1.73 \%$ & 142 & $1.38 \%$ \\
\hline & Australian Indigenous Languages & 1 & $0.02 \%$ & 0 & $0.00 \%$ & 1 & $0.01 \%$ & 0 & $0.00 \%$ & 0 & $0.00 \%$ & 0 & $0.00 \%$ \\
\hline & Other Languages & 2 & $0.05 \%$ & 12 & $0.21 \%$ & 14 & $0.14 \%$ & 4 & $0.10 \%$ & 27 & $0.43 \%$ & 31 & $0.30 \%$ \\
\hline & Supplementary codes & 0 & $0.00 \%$ & 4 & $0.07 \%$ & 4 & $0.04 \%$ & 0 & $0.00 \%$ & 20 & $0.32 \%$ & 20 & $0.19 \%$ \\
\hline & Missing Data & 46 & $1.08 \%$ & 213 & $3.70 \%$ & 259 & $2.58 \%$ & 64 & $1.58 \%$ & 222 & $3.56 \%$ & 286 & $2.78 \%$ \\
\hline & Australia & 2,905 & $68.10 \%$ & 3,170 & $55.00 \%$ & 6,075 & $60.57 \%$ & 2,417 & $59.83 \%$ & 2,859 & $45.86 \%$ & 5,276 & $51.35 \%$ \\
\hline Birth* & Southern and Eastern Europe & 614 & $14.39 \%$ & 1,140 & $19.78 \%$ & 1,754 & $17.49 \%$ & 667 & $16.51 \%$ & 1,220 & $19.57 \%$ & 1,887 & $18.37 \%$ \\
\hline & North-West Europe & 5 & $0.12 \%$ & 4 & $0.07 \%$ & 9 & $0.09 \%$ & 1 & $0.02 \%$ & 1 & $0.02 \%$ & 2 & $0.02 \%$ \\
\hline
\end{tabular}

This article is protected by copyright. All rights reserved 


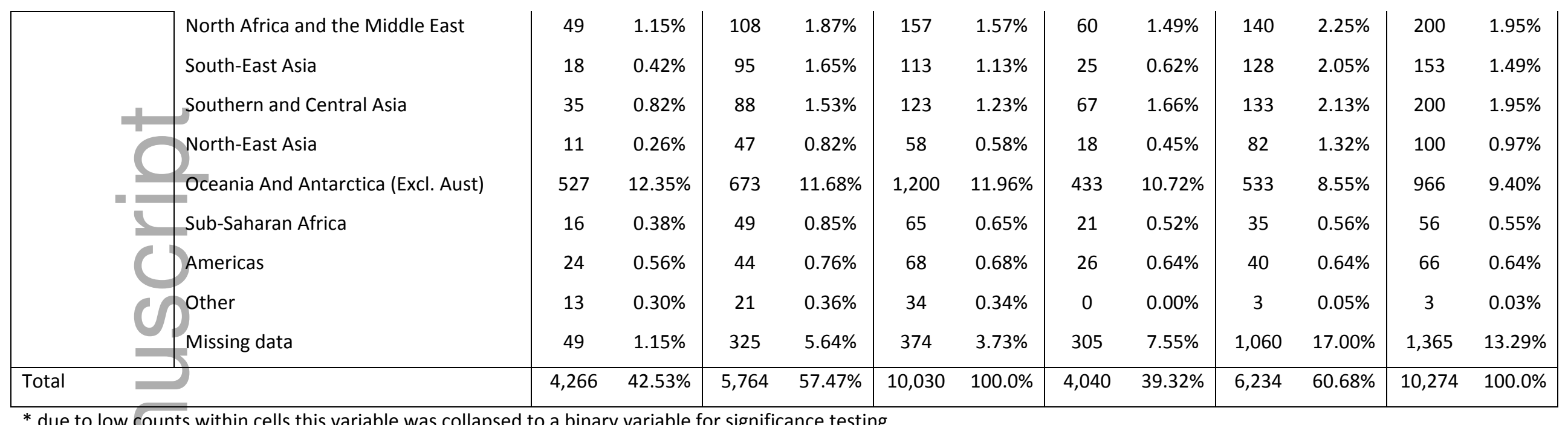

* due to low counts within cells this variable was collapsed to a binary variable for significance testing

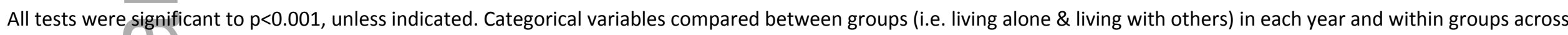
years (i.e. living alone in 2006 and 2015) using Chi2 goodness of fit, continuous variables compared using independent samples t-test.

† The socioeconomic status of women living with others did not differ between 2006 and $2015 \chi 2(5, n=11,998)=2.92, p=0.713$

¥ The carer relationship profile did not differ for women living with others between 2006 and $2015 \chi 2(9, n=11,998)=16.12, p=0.064$

$\S$ The proportion of women living with others who spoke English did not differ between 2006 and $2015 \chi 2(1, n=11,998)=5.42, p=0.020$

Table 2. Service profile

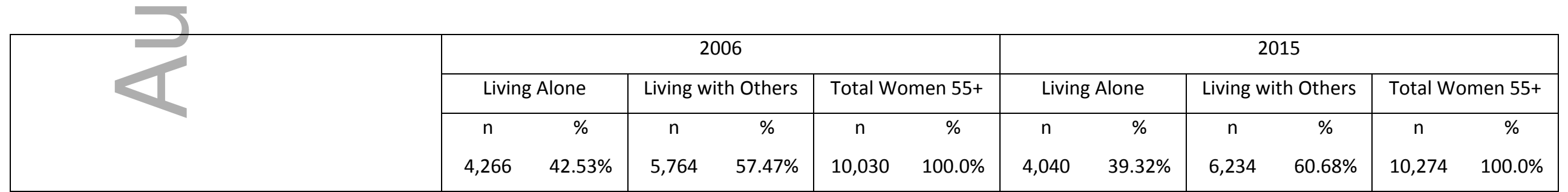

This article is protected by copyright. All rights reserved 


\begin{tabular}{|c|c|c|c|c|c|c|c|c|c|c|c|c|c|}
\hline Referral & Individuals & 511 & $11.98 \%$ & 638 & $11.07 \%$ & 1149 & $11.46 \%$ & 590 & $14.60 \%$ & 771 & $12.37 \%$ & 1361 & $13.25 \%$ \\
\hline \multirow[t]{8}{*}{ Source } & Hospital & 1,404 & $32.91 \%$ & 2,556 & $44.34 \%$ & 3960 & $39.48 \%$ & 1,388 & $34.36 \%$ & 2,488 & $39.91 \%$ & 3876 & $37.73 \%$ \\
\hline & Doctor (GP/ Specialist) & 841 & $19.71 \%$ & 782 & $13.57 \%$ & 1623 & $16.18 \%$ & 663 & $16.41 \%$ & 627 & $10.06 \%$ & 1290 & $12.56 \%$ \\
\hline & liative Care & 49 & $1.15 \%$ & 341 & $5.92 \%$ & 390 & $3.89 \%$ & 102 & $2.52 \%$ & 516 & $8.28 \%$ & 618 & $6.02 \%$ \\
\hline & Subacute Care & 1,005 & $23.56 \%$ & 713 & $12.37 \%$ & 1718 & $17.13 \%$ & 595 & $14.73 \%$ & 641 & $10.28 \%$ & 1236 & $12.03 \%$ \\
\hline & Services & 142 & $3.33 \%$ & 183 & $3.17 \%$ & 325 & $3.24 \%$ & 241 & $5.97 \%$ & 534 & $8.57 \%$ & 775 & $7.54 \%$ \\
\hline & Nursing Home & 93 & $2.18 \%$ & 118 & $2.05 \%$ & 211 & $2.10 \%$ & 27 & $0.67 \%$ & 48 & $0.77 \%$ & 75 & $0.73 \%$ \\
\hline & Other & 221 & $5.18 \%$ & 433 & $7.51 \%$ & 654 & $6.52 \%$ & 434 & $10.74 \%$ & 609 & $9.77 \%$ & 1043 & $10.15 \%$ \\
\hline & Missing & 0 & $0.00 \%$ & 0 & $0.00 \%$ & 0 & $0.00 \%$ & 0 & $0.00 \%$ & 0 & $0.00 \%$ & 0 & $0.00 \%$ \\
\hline Goal Outcome & Not Achieved & 1,344 & $31.50 \%$ & 1,488 & $25.82 \%$ & 2,832 & $28.24 \%$ & 1,617 & $40.02 \%$ & 1,881 & $30.17 \%$ & 3,498 & $34.05 \%$ \\
\hline Achieved & Achieved & 2,922 & $68.50 \%$ & 4,276 & $74.18 \%$ & 7,198 & $71.76 \%$ & 2,423 & $59.98 \%$ & 4,353 & $69.83 \%$ & 6,776 & $65.95 \%$ \\
\hline Discharge & Missing & 0 & $0.00 \%$ & 0 & $0.00 \%$ & 0 & $0.00 \%$ & 0 & $0.00 \%$ & 0 & $0.00 \%$ & 0 & $0.00 \%$ \\
\hline Discharge & tome & 2,680 & $62.82 \%$ & 4,050 & $70.26 \%$ & 6,730 & $67.10 \%$ & 2,502 & $61.93 \%$ & 4,548 & $72.95 \%$ & 7,050 & $68.62 \%$ \\
\hline \multirow[t]{6}{*}{ Location } & Hospital & 898 & $21.05 \%$ & 1,021 & $17.71 \%$ & 1,919 & $19.13 \%$ & 907 & $22.45 \%$ & 986 & $15.82 \%$ & 1,893 & $18.43 \%$ \\
\hline & Nursing Home & 219 & $5.13 \%$ & 183 & $3.17 \%$ & 402 & $4.01 \%$ & 195 & $4.83 \%$ & 220 & $3.53 \%$ & 415 & $4.04 \%$ \\
\hline & Iliative Care & 46 & $1.08 \%$ & 118 & $2.05 \%$ & 164 & $1.64 \%$ & 37 & $0.92 \%$ & 99 & $1.59 \%$ & 136 & $1.32 \%$ \\
\hline & Subacute Care & 42 & $0.98 \%$ & 43 & $0.75 \%$ & 85 & $0.85 \%$ & 31 & $0.77 \%$ & 37 & $0.59 \%$ & 68 & $0.66 \%$ \\
\hline & Missing & 32 & $0.75 \%$ & 6 & $0.10 \%$ & 38 & $0.38 \%$ & 243 & $6.01 \%$ & 177 & $2.84 \%$ & 420 & $4.09 \%$ \\
\hline & Other & 349 & $8.18 \%$ & 343 & $5.95 \%$ & 692 & $6.90 \%$ & 125 & $3.09 \%$ & 167 & $2.68 \%$ & 292 & $2.84 \%$ \\
\hline Total & & 4,266 & $42.53 \%$ & 5,764 & $57.47 \%$ & 10,030 & $100.0 \%$ & 4,040 & $39.32 \%$ & 6,234 & $60.68 \%$ & 10,274 & $100.0 \%$ \\
\hline
\end{tabular}

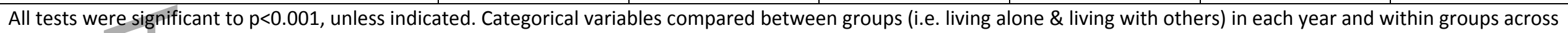
years (i.e. living alone in 2006 and 2015) using Chi2 goodness of fit.

This article is protected by copyright. All rights reserved 
Table 3. Diagnosis profile

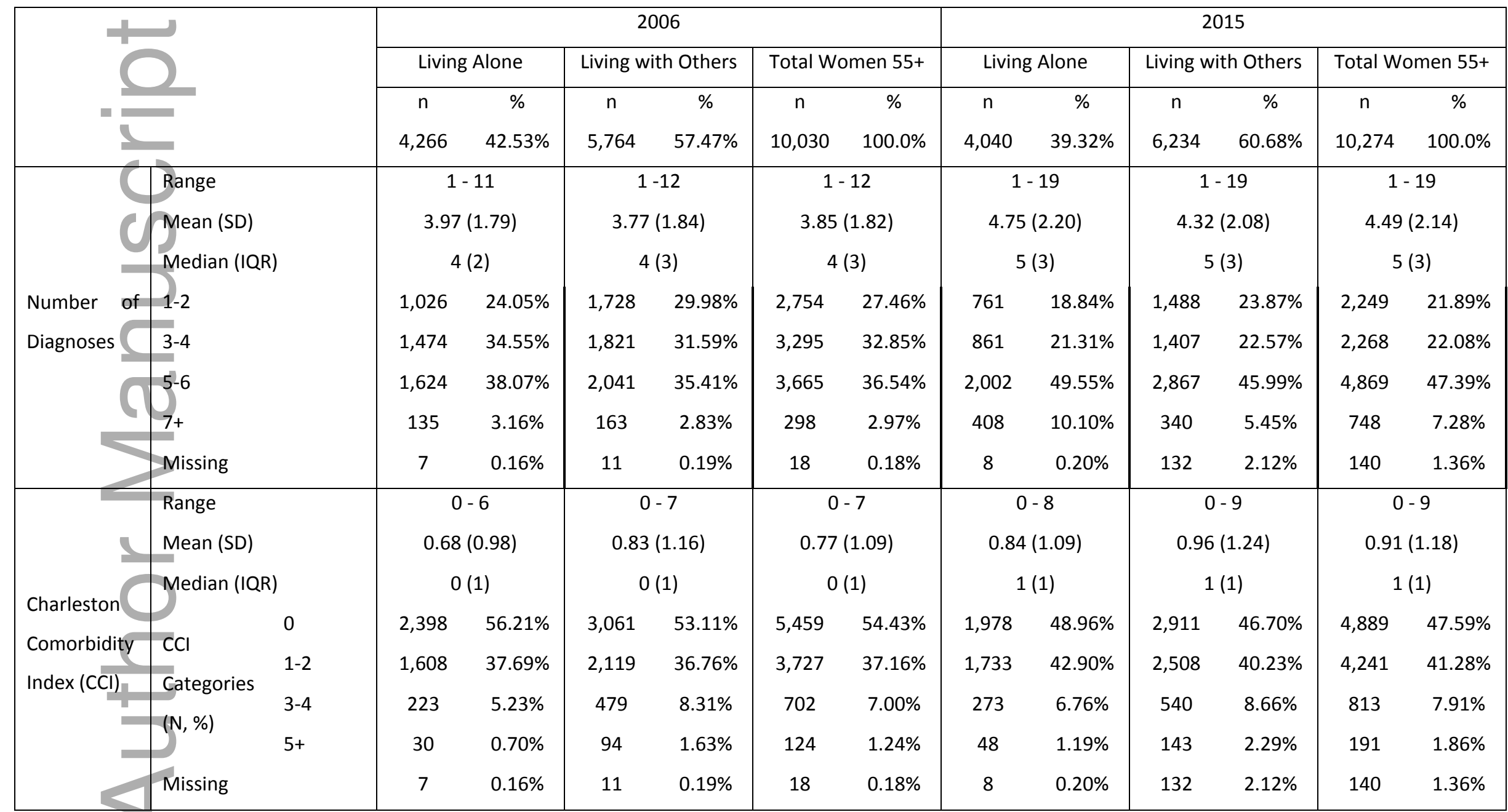

All tests were significant to $p<0.001$, unless indicated. Categorical variables compared across years (i.e. living alone in 2006 and 2015 ) using Chi2 goodness of fit, continuous variables compared using independent samples t-test

This article is protected by copyright. All rights reserved 


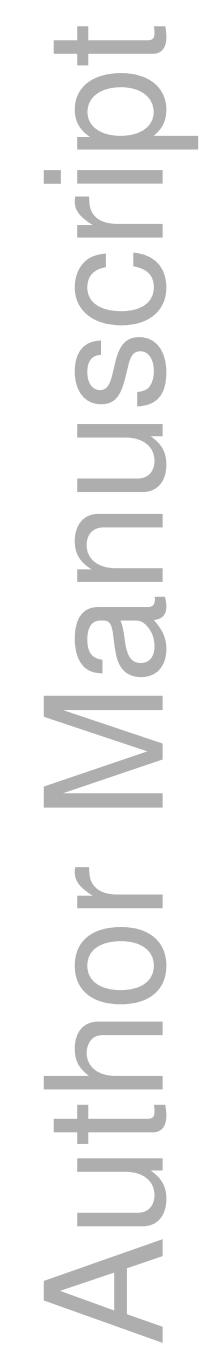

This article is protected by copyright. All rights reserved 


\begin{tabular}{|c|c|c|}
\hline Comparing the years 2006 and $2015 \ldots$ & ...in 2015, OWLA were: & ...in 2015, OWLO were: \\
\hline \multicolumn{3}{|l|}{ Sociodemographic Profile } \\
\hline Age & older & older \\
\hline Born in Australia & less likely & less likely \\
\hline Speak English as their preferred language & less likely & less likely \\
\hline Live in areas of least socioeconomic disadvantage & more likely & no difference \\
\hline Have an informal carer & less likely & less likely \\
\hline \multicolumn{3}{|l|}{ Service Profile } \\
\hline Achieved their care goal & less likely & less likely \\
\hline \multicolumn{3}{|l|}{ Referred to home nursing by... } \\
\hline a hospital & more likely & less likely \\
\hline palliative care & more likely & more likely \\
\hline a doctor & less likely & less likely \\
\hline subacute care & less likely & less likely \\
\hline \\
\hline $\begin{array}{l}\text { home } \\
\text { hospital }\end{array}$ & $\begin{array}{l}\text { less likely } \\
\text { more likely }\end{array}$ & $\begin{array}{l}\text { more likely } \\
\text { less likely }\end{array}$ \\
\hline \multicolumn{3}{|l|}{ Diagnosis Profile } \\
\hline Number of diagnoses & more likely & more likely \\
\hline $\mathrm{CCl}$ score & more likely & more likely \\
\hline
\end{tabular}

Note: $\mathrm{CCl}$ - Charlson Comorbidity Index; all changes were statistically significant $p<0.001$

Figure 1. Summary comparing changes in socio-demographic profile and service use of Older Women Living Alone (OWLA) and Older Women Living with Others (OWLO), 2006 and 2015

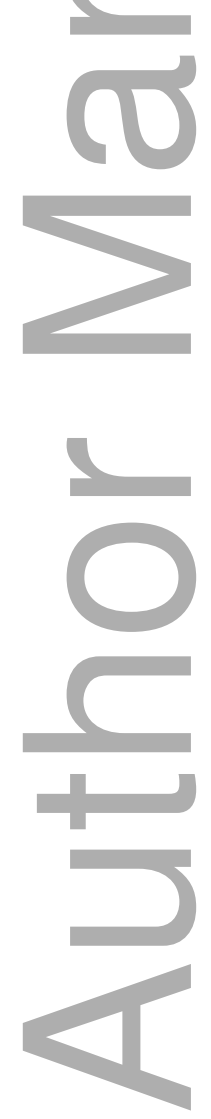


290

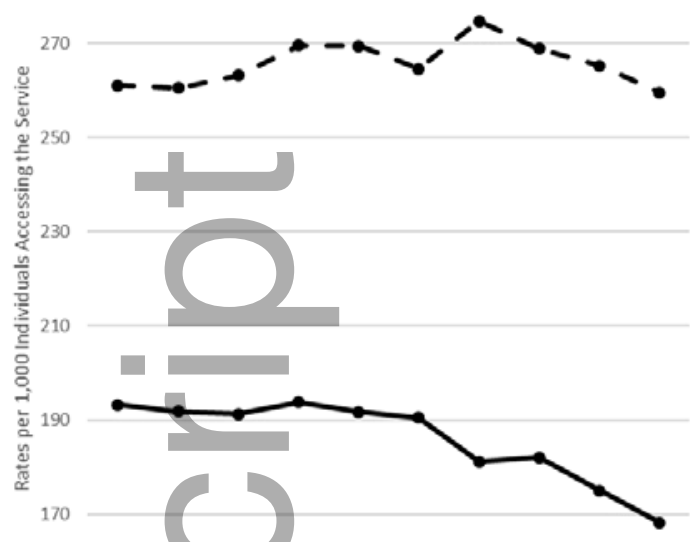

150

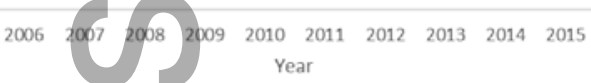

$\longrightarrow$ Rate Women Living Alone by Total Persons

——- Rate Women Living with others by Total Persons

2c. Relative rates - living alone by age group

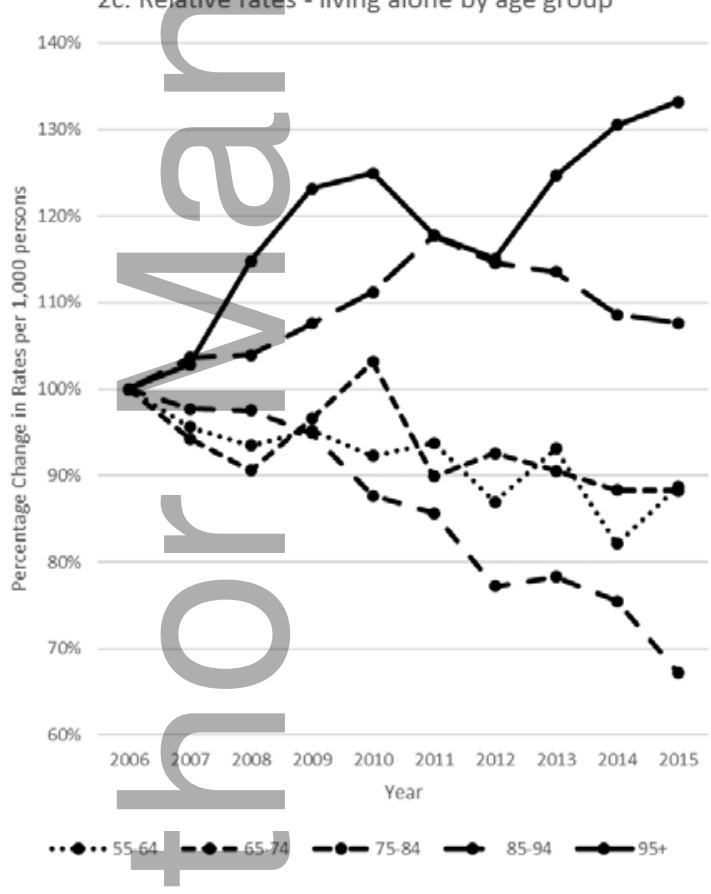

$2 \mathrm{~b}$. Relative rates

$110 \%$

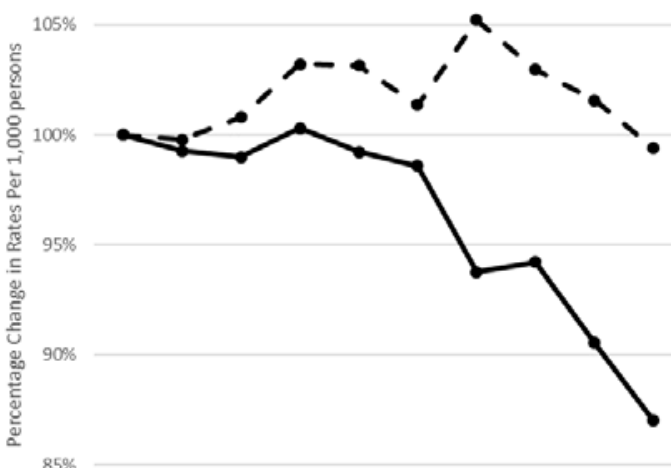

$80 \%$

$\begin{array}{llllllllll}2006 & 2007 & 2008 & 2009 & 2010 & 2011 & 2012 & 2013 & 2014 & 2015\end{array}$ Year

$\longrightarrow$ Rate Women Living Alone by Total Persons

- •- Rate Women Living with others by Total Persons

$2 \mathrm{~d}$. Relative rates - living with others by age group

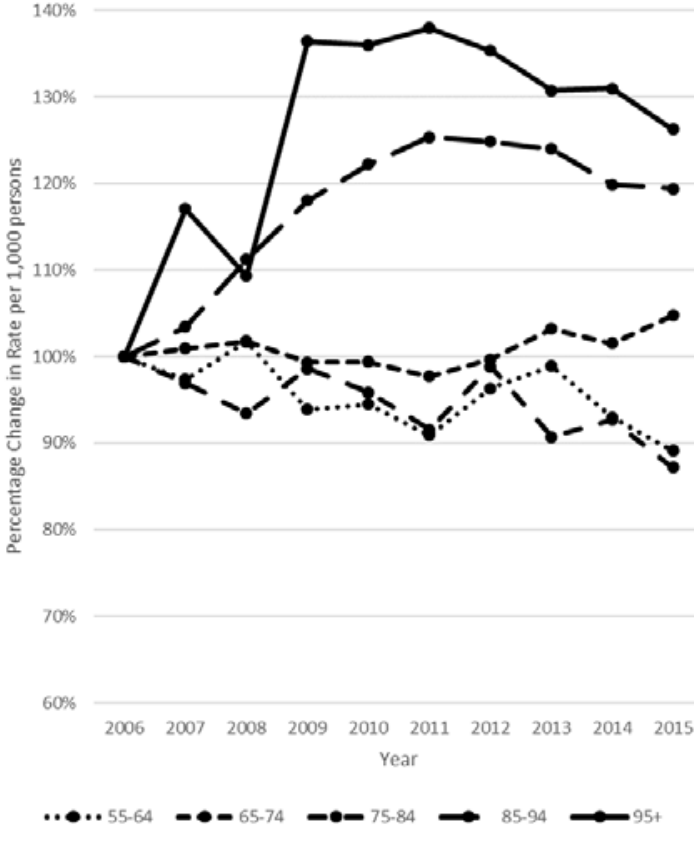

Figure 2. Rates and relative rates of Older women (aged 55 years and over) per 1,000 clients (all ages and sexes) accessing community home nursing; Rates and relative rates broken down by living alone status; Relative rates broken down by age group.

This article is protected by copyright. All rights reserved 


\section{University Library}

\section{- M M N E R VA A gateway to Melbourne's research publications}

Minerva Access is the Institutional Repository of The University of Melbourne

Author/s:

Dickins, M;Joe, A;Enticott, J;Ogrin, R;Lowthian, J

Title:

Trajectories of home nursing use for older women in Melbourne, Australia: 2006-2015

Date:

2019-10-15

Citation:

Dickins, M., Joe, A., Enticott, J., Ogrin, R. \& Lowthian, J. (2019). Trajectories of home nursing use for older women in Melbourne, Australia: 2006-2015. AUSTRALASIAN JOURNAL ON AGEING, 39 (3), pp.E295-E305. https://doi.org/10.1111/ajag.12735.

Persistent Link:

http://hdl.handle.net/11343/286502 